\title{
Shared Academic Library Facilities: The Unknown Form of
}

\section{Library Cooperation}

\section{Anthony J. Dedrick}

Although cooperative efforts such as interlibrary loan, collection development, and shared databases are well documented in the literature, there is little information available regarding shared academic library facilities. Along with this lack of information is the growing interest in such arrangements. This paper reports the results of a survey of shared facilities and some of the typical organizational and management structures. In addition, the question of which organizational model works best is discussed. In general, the survey found that there are significant cost savings and service enhancements resulting from a shared facility arrangement along with some additional administrative overhead.

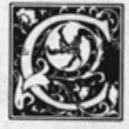

ooperative library efforts have a long history in America and have increased at a rapid rate, particularly since the mid-1960s. One of the oldest and best-known of these efforts was the Joint University Libraries (JUL) of Nashville which began operation in 1938 and continued until 1980 when it became Vanderbilt University Libraries, following an institutional merger. Traditional cooperative efforts such as interlibrary loan, document delivery, collection development, and shared databases are well documented in the literature. However, one type of cooperation is rarely reported. This is the shared academic library facility. The need for a survey is indicated by (1) the lack of information regarding this type of library cooperation, despite the fact that these types of arrangements have been in existence for some time (this survey identified several programs that have been in operation for over twenty years); and (2) the heightened interest in this type of cooperation as evidenced by the number of inquiries this author has received and by the increase in the literature citations over the last several years regarding shared facilities.

The primary objectives of this study were to identify a core of shared library facilities and to determine if there were any common patterns of development, organizational structures, and concerns. Likewise it was hoped that the study would provide libraries contemplating a shared facility with some information about the organizational and funding arrangements in use and what aspects of joint facility programs have been successful or unsuccessful.

A literature search was conducted back to 1975 and was supplemented with a review of Stenstrom's Cooperation between Types of Libraries 1940-1968.' The only pertinent literature found was fairly recent. Joseph Lindenfeld's work is a description of six community 
college/public library cooperative ventures. ${ }^{2}$ Susan Anderson's contributions include a survey of Florida joint-use facilities (1988), a follow-up article on that same topic published in 1990 and a short one-page discussion within her contributed chapter to Academic Libraries in Urban and Metropolitan Areas in 1992. ${ }^{3-5}$ Tom Connole describes a public library/community college arrangement in Colorado while Yvonne Ralston and Adele Oldenburg focus on a general planning process for university and community college joint-use libraries. ${ }^{6,7}$

The impetus for this particular study came as an outgrowth of a consulting project completed for Edison Community College and the University of South Florida in $1986 .{ }^{8}$ As a part of the project, an attempt was made to identify other shared academic library facilities. A number of institutions, primarily in Florida and Texas, in addition to the Auraria Higher Education Center in Colorado, were identified. This list was then expanded with the assistance of Susan Anderson at St. Petersburg Junior College in 1991 and a series of telephone interviews was completed with the directors of libraries from this composite list. These individuals, in turn, were queried as to any additional shared facility arrangements of which they were aware. This networking process resulted in the final list of institutions surveyed in this study.

\section{OVERVIEW}

A twelve-item survey (appendix A) was developed and distributed to the targeted institutions (a list of these institutions is available from the author). Most data reported were taken from information supplied by respondents; this was supplemented as needed by data from the ALA Directory, 44th ed., 1991. A number of the surveys were returned with somewhat ambiguous responses. That is, "other" was checked with no explanation, "not applicable" was indicated, or the question was not answered at all. When "other" was marked and an explanation given, those comments were summarized. In retrospect, a num- ber of the questionnaire items should have been clarified, in particular the item dealing with budgetary status after the shared program was implemented. In particular, it would have been useful to determine if the percentage of the institutional budgets allocated to library services changed after the merger process. Likewise, the number of responses per question item was uneven. Followup calls to many of the respondents were made to clarify information; unfortunately the time limits for project completion resulted in some responses remaining unclarified. One joint program arrangement, Valencia Community College, has been dissolved. However, those data were considered important and were included. Despite these limitations, the survey should prove valuable to the profession, particularly in an era of increasing interinstitutional cooperation. Corrections to the data supplied would be appreciated and readers are urged to contact the author if they either participate in a shared library not covered in this survey, have corrections to the data reported, or are aware of other systems not covered.

\section{SURVEY RESULTS}

The first two questions dealt with the age of joint services programs and the number of institutions involved in each program. The longevity of the joint services initiatives was the most surprising aspect of this set of responses. The average age of the joint services programs was almost thirteen years (12.96); two of the programs were twenty-four and twenty-five years old; sixteen were ten or more years old; and only five were less than seven years old. The fact that the majority of the programs were over ten years old would seem to indicate that the shared facility concept is a viable one. More than three-fourths of the shared ventures entailed two institutions, although there were four programs involving three institutions and two involving four institutions. In terms of the types of institutions involved in joint use ventures, the most common pattern was a community college and 
university or college (typically a university branch campus). There were eleven of these types of arrangements. The next largest group (six programs) consisted of a community college and a public library entity. Two states, Texas and Florida, are clearly the leaders in joint use library ventures (over one-half of the programs reported are located in these two states). A fairly common developmental pattern has been the older, established community college campus which then gets involved in a joint venture with a new or rapidly expanding university branch program. Beyond the two patterns noted above, there is a wide diversity of arrangements: public and school; community college, four-year and university; and community college, university, and public, among others. All but one of the programs involve a community college library. Why community college libraries are so dominant in the joint library area is probably because the community orientation of such institutions results in a shared mission with local public libraries. In addition, the long-established community colleges in Texas and Florida often were on location before branch university campuses or programs were established or expanded.

\section{The fact that the majority of the programs were over ten years old would seem to indicate that the shared facility concept is a viable one.}

The management of joint services programs is highly diverse. Thirteen of the programs have one library director, but five of those programs have employees paid by both institutions. Eight programs have separate library directors for each participating institution. In terms of administrative reporting lines, seventeen directors report to one administrative official and six report to an institutional official from each of the participating institutions. Examples of other types of reporting lines include the Roundup Community Library Director who reports to a high school principal and acts as an adviser to the governing board, and the Mississippi County Library System and College Library Director who reports to a public library board and the college president.

Funding for the joint programs was, like the management structures, highly diverse. This question had the largest number of respondents indicating "other" and reflects the diversity of funding arrangements for joint library ventures. In general, these responses tended to show no consistency from one shared library to another and result from the variances in local situations such as institutional history and the different approaches to library support for the respective institutions. Interestingly enough, there were several respondents who indicated that the library funding was either subject to negotiations annually or was at the discretion of the institutions involved; there was no set policy or agreement. Approximately one-third of the programs were funded by having each institution responsible for specific services. Examples of specific services (or areas of budgetary responsibility) separated by institution include book budget, the technical services operation, and physical facility, including custodial, maintenance, and utilities, and interlibrary loan. Four institutions reported that a percentage of each institution's budget is used as a basis for supporting the library and four utilized numbers of students as a basis for support. In several instances types of funding were combined. That is, the library allocation was based on a percent of the institutional budget, and that amount was applied to specific services or items within the shared library.

Twelve libraries responded that institutional library funding increased once the joint program was established, nine reported that it stayed the same, and five did not supply the information. This pattern would suggest that the concerns raised by several respondents are not valid. That is, a joint program is more efficient and consequently institutions will use that as a pretext for reducing library funding. In retrospect, it would 
have been useful to expand this question so that a determination could be made if the increases were routine incremental amounts or if they were additional funds.

Seventy-five percent of the programs responded that some type of separate budget accounting is maintained for each school. The type of accounting/budget practices varied widely. Examples included assigning individual books purchased to separate institutional accounts (driven by source of purchase requests) to maintaining separate budgeting and tracking systems for those specific services paid for by the sister institution-that is, the costs associated with the operation of a particular service would be tracked according to the policies of the institution providing the funds for that service.

In terms of preference for a shared library system versus several, smaller stand-alone institutional library programs, eighteen respondents thought the shared approach was better, while six said that a stand-alone arrangement would be better than their current situation. The narrative responses and comments from this question along with the responses to item 12 ("pluses and minuses of the joint library program") are discussed in the conclusion of this article.

Surprisingly, three of the programs surveyed did not have a written library services agreement. Several did provide copies of the agreements and, again, there was considerable diversity both in terms of content and level of detail.

Item 12 addressed any anticipated substantive change(s) to the program and/or future changes. The responses typically tended to focus on issues such as budgetary concerns, new facility construction, and networking. Interestingly enough, two programs reported that the joint effort will be discontinued once permanent and separate campuses are built for the respective institutions. In both of these cases, the branch university campus was operating out of temporary facilities and, essentially, utilized (and supplemented) the existing, permanent community college facility.

\section{CONCLUSIONS}

The final section of this article will summarize what respondents viewed as both the "pluses" and "minuses" of their joint services program, along with additional narrative comments not reported earlier. This section also reflects the observations obtained through numerous follow-up telephone conversations during the course of this survey, the author's eighteen years' experience with a shared facility, and the literature on this topic.

The specific "plus" comments can be grouped into two general categories: costs and services. In terms of costs, the primary advantages reported were:

- Larger acquisitions budget

- Better utilization of staff

- Reduced physical plant costs such as utilities and maintenance

- Elimination of the costs for a new facility

- Better discounts through volume purchasing.

In terms of service, the primary benefits reported were:

- Access to a much larger collection

- Ability to purchase expensive reference materials and products, for example, CD-ROMs

- Expanded hours of service

- Better access to technology such as an online catalog.

Virtually all of the negative comments were focused on the administrative difficulties inherent in a shared library program. These administrative issues tended to fall into the following categories:

- Tracking multiple budgets

- Developing programs and services to meet the needs of separate institutions with different missions and student populations

- Communication difficulties

- Managing staff who operate under two separate payroll systems and institutional personnel policies

- Lack of clarity regarding the amount and value of institutional contributions to the joint program

- For those programs involving an academic institution and a nonacademic program such as a public or school 
library, the different focus and types of programs are especially difficult to manage.

As reported earlier, six of the institutions indicated a preference for a standalone environment in lieu of their current shared environment. None of the six respondents went into significant detail as to why they preferred a standalone system. Three of them gave no reasons whatsoever, one reported that the college used the joint program as a pretext for ignoring library needs, one cited the difficulty in meeting individual campus needs (but did note the shared program was cost-effective), and the last institution made only one negative comment (difficulty in trying to serve two institutions equally) while citing numerous positive aspects of the joint arrangement. None of these respondents indicated a strong preference for a standalone system. This is in contrast to the eighteen respondents who preferred the joint-use approach. Over one-half of them were extremely positive in their supplementary comments.

\section{Given the increasingly tight budget situations for most libraries, the cooperative facility alternative should be an increasingly attractive option in the future.}

Two clear patterns emerge from this study: (1) the typical shared academic library facility program does provide significant cost savings and service enhancements, and (2) there are inherently additional administrative burdens with these types of arrangements. The question remains, are the additional administrative problems offset by the cost savings and service enhancements? Given the increasingly tight budget situations for most libraries, the cooperative facility alternative should be an increasingly attractive option in the future.

Finally, some partial answers can be deduced from this study relative to which type of organizational model works best and what issues need to be evaluated by an institution considering a shared facility program. Organizational and funding structures usually are driven by unique local circumstances, including issues of what is politically acceptable, perceived benefits to the participants, historical patterns of cooperation, statutory restrictions and financial need. Consequently, there is no one best model; it is more useful for participants to select whatever arrangement will best fit into their respective institutional environments and best meet their needs. Nonetheless, there are clearly some approaches that require much less administrative overhead than others. An example would be a program such as that at the Auraria Library where all operations, including staff and financial processes, are consolidated and function under one set of institutional rules and regulations (the Auraria Library is part of the University of Colorado at Denver, reports to that institution, and all staff are employees of that institution). This arrangement eliminates the burdensome problem of maintaining dual accounting/reporting structures and managing a staff with dual personnel and payroll structures.

It appears from the study that early detailed planning is critical for an institution contemplating a shared facility. The work done by Ralston and Oldenburg provides an excellent guide for this planning process. Prior to that detailed planning process, it is also essential that the prospective participants see a real value in the proposed program to their respective institutions and that the effort is undertaken with a sense of cooperation and flexibility.

Ultimately, the best sources of information from this study could very well be the contact list of cooperative programs. This group of libraries represents a substantial pool of experience and can provide some insights into the somewhat nebulous, but absolutely critical, issues related to intra-institutional politics and turf that come into play with a shared library facility program. 


\section{REFERENCES AND NOTES}

1. Ralph H. Stenstrom, Cooperation between Types of Libraries (Chicago: ALA, 1970), 7.

2. Joseph F. Lindenfeld, "Six Patterns of Community College/Public Library Cooperation," Community and Junior College Libraries 2 (1984): 33-41.

3. Susan Anderson, "Resource Sharing: A Study of Florida Shared Use Library Collections" (Ph.D. diss., Nova University, Fort Lauderdale, Fla., 1988).

4. Susan Anderson, "Shared Libraries: Focus on Florida," Community and Junior College Libraries 7 (1990): 3-15.

5. Susan Anderson, "The Perception of Distance: Networking among Libraries," in Academic Libraries in Urban and Metropolitan Areas, ed. Gerard B. McCabe (Westport, Conn.: Greenwood, 1992), 131-42.

6. Tom Connole, "Providing Library Services in a Non-Traditional Mode at the Community College of Aurora," Colorado Libraries (Sept., 1991), 9-11.

7. Yvonne L. Ralston and Adele Oldenburg, "Joint-Use Library Services at Distant Campuses: Building Cooperation between a Community College and a University," in Academic Libraries in Urban and Metropolitan Areas, 143-56.

8. Anthony J. Dedrick, "Intensity of Use Study-Edison Community College/University of South Florida Report" (unpublished consulting report prepared for the University of South Florida, 1986).

\section{APPENDIX A \\ (Survey Instrument) \\ Shared Library Survey}

Institution(s)

Contact Person

Title

Date

Physical Description of Facility: Sq. Ft.

Reader Stations

Branch Libraries (please list)

1. Year the joint library service program was initiated

2. How many institutions are involved in your joint use library?
a. 2
b. 3
c. 4
d. 5 or more

3. How is the joint services program managed?
a. Staff report to one joint services library director
b. Staff report to one joint services library director but are employees of different institution
c. Staff report to separate library directors for each participating institution
d. Other (please explain)

4. What is the line of administrative authority?
a. The library director reports to one institutional official
b. The library director reports to an institutional official from each participating institution
c. The library director reports to a board
d. Other (please explain) 
5. If a board exists, what is its function?
a. An advisory board with no governing authority
b. A governing board with decision-making authority
c. No board
d. Other (please explain)

6. How is the joint library funded?
a. FTE (Full-Time-Equivalent) based
b. Head-Count based
c. Each institution is responsible for specific services
d. Percentage of each institution's budget
e. Other (please explain)

7. Did the funding for library services by each institution change after the joint library program was established?
a. Increased
b. Decreased
c. Stayed same

8. Is the joint library budget separated or "tracked" by institution-i.e., a separate acquisitions budget for each school, etc.?
a. Yes
b. No

9. Do you feel that your approach is preferable to several, smaller stand-alone institutional library programs?
a. Yes
b. No

10. Is there a written library services agreement, and, if so, can I obtain a copy?
a. Yes
b. No

11. Would you briefly summarize any anticipated substantive change(s) to the existing program and/or future plans.

12. What are pluses and/or minuses of the joint library program based on your experience to date?

13. Do you wish to have a copy of the survey results sent to you?
a. Yes
b. No 


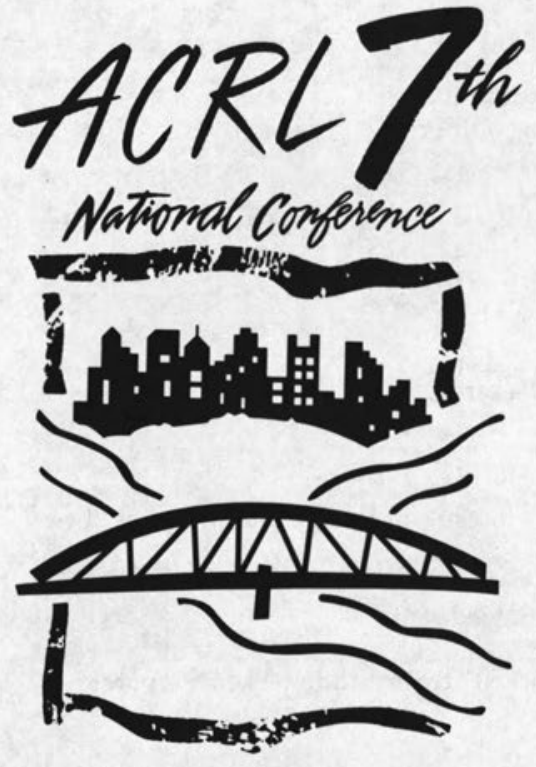

- Join your colleagues in Pittsburgh

- Learn the latest in academic library research and practice

- See exhibits of products and services for libraries

- March 29 - April 1, 1995

- Register now! Call (800) 545-2433, ext. 2521

"Continuity and Transformation ... ... The Promise of Confluence"

Association Of C OL LEGE \& RESEARCH LIBRARIES

\section{APPLICATIONS/NOMINATIONS INVITED FOR C\&RL EDITOR}

Applications and nominations are invited for the position of editor of COLLEGE \& RESEARCH LIBRARIES (C\&RL), the bimonthly, scholarly research joumal of the Association of College and Research Libraries (ACRL). The editor is appointed for a three-year term which may be renewed for an additional three years. Applicants must be members of ALA and ACRL. Qualifications include professional experience in academic libraries, a record of scholarly publication, editing experience, an understanding of the scholarly communication process, and a broad knowledge of the issues confronting academic libraries.

Some funding for editorial assistance is available, and there is a small honorarium for the editor.

Appointment will be made by the ACRL Board of Directors at the 1995 Annual Conference, upon the recommendation of the search committee and of the ACRL Publications Committee. The ir.coming editor will assume full responsibility for C\&RL in July 1996, after a year working with the out-going editor.

Nominations, or resumes and letters of application including the names of three references, should be sent to:

\section{C\&RL Search Committee \\ c/o Hugh Thompson, Program Officer ACRLIALA \\ 50 E. Huron Street \\ Chicago, IL 60611}

The deadline for receipt of applications is December 15, 1994. Finalists will be interviewed at the Midwinter Meeting in February 1995. 